\title{
Validity of a Questionnaire for Periodontitis Screening of Japanese Employees
}

\author{
Tatsuo Yamamoto, Reiko Koyama, Naofumi Tamaki, Takayuki Maruyama, \\ Takaaki Tomofuji, Daisuke Ekuni, Reiko Yamanaka, Tetsuji Azuma and Manabu Morita \\ Department of Preventive Dentistry, Okayama University Graduate School of Medicine, Dentistry and \\ Pharmaceutical Sciences, Japan
}

\begin{abstract}
Validity of a Questionnaire for Periodontitis Screening of Japanese Employees: Tatsuo Yамамото, et al. Department of Preventive Dentistry, Okayama University Graduate School of Medicine, Dentistry and Pharmaceutical SciencesObjectives: Workplaces are suitable for screening for periodontal disease effectively. However, the majority of workplaces do not have a screening program. One possible reason may be that pocket probing, which is commonly used for the screening, needs qualified examiners and is time-consuming. In this study, the validity of a self-reported questionnaire was assessed for screening of periodontitis in 50- to 59-yr-old male employees in Japan. Methods: A total of 250 people were asked to complete a self-administered questionnaire regarding signs and symptoms of periodontal disease, and experience of periodontal treatment, followed by a clinical examination by a dentist. Subjects with at least one tooth having a clinical attachment loss of $7 \mathrm{~mm}$ or more were defined as periodontitis patients. Results: Thirteen percent of the subjects were diagnosed as having periodontitis. Logistic regression selected 4 questions, "Are you a current or past smoker?", "Have your gums bled recently?", "Do you think that you can see more roots of teeth than in the past?", and "Have you ever been told that you need periodontal or gum treatment?" as potential predictors of periodontitis. When subjects with at least 3 "yes" responses to the 4 questions were separated from the others, the subjects with periodontitis were separated most effectively (showing the highest sensitivity + specificity: 1.524 ) from those without. The area under the receiver operating
\end{abstract}

Received Jul 31, 2008; Accepted Jan 8, 2009

Published online in J-STAGE Feb 6, 2009

Correspondence to: T. Yamamoto, Department of Preventive Dentistry, Okayama University Graduate School of Medicine, Dentistry and Pharmaceutical Sciences, 2-5-1 Shikata-cho, Okayama 700-8525, Japan (e-mail: tatsuo@md.okayama-u.ac.jp) characteristic curve was 0.81 . Conclusions: These results suggest that the self-reported questions are useful for screening of periodontitis in 50- to 59-yr-old Japanese workers.

(J Occup Health 2009; 51: 137-143)

Key words: Periodontitis, Questionnaires, Receiver operating characteristic curve, Screening, Selfassessment, Sensitivity, Specificity

Periodontal disease is one of the most prevalent diseases affecting human dentition and one of the principal causes of tooth loss ${ }^{1)}$. Gingivitis, a milder form of periodontal disease, is commonly found among individuals of all age groups. Periodontitis, which affects the deeper tissues of the periodontium, including alveolar bone, is more prevalent in the older age group than in young persons ${ }^{2)}$.

Workplaces are suitable for screening for periodontal disease because most of the target population would be involved. However, many workplaces do not have a system for screening for periodontal disease ${ }^{3)}$. One possible reason may be that dental health check-ups are not mandated by law. There are other possible reasons why screening for periodontal disease is not performed at workplaces. The Community Periodontal Index (CPI) is often used for the screening of periodontal disease in public health ${ }^{4}$; however, qualified examiners are needed to perform the probing procedure. Considerable time and effort are also required when screening for periodontal disease in a large number of subjects. In addition, some people find periodontal probing uncomfortable ${ }^{5)}$.

Questionnaires may be employed for screening for periodontal disease. Self-reported questionnaires are considered for determining and monitoring prevalence of periodontal disease in the United States ${ }^{6}$ because of their cost-efficiency. Self-reported periodontal measures were validated in US studies using health professionals 
as subjects ${ }^{7,8)}$. On the other hand, studies using general populations did not show satisfactory validity when a single self-reported item was used to assess periodontal disease history in the United Kingdom ${ }^{9}$, the United States $^{10)}$, Sweden ${ }^{11)}$, and Germany ${ }^{12)}$; however, recent reports showed that a multivariate predictive model including self-reported items and basic demographic variables was sufficiently valid ${ }^{6,13-16)}$. The validity of self-reported questions may vary from country to country. In the present study, the validity of a self-reported questionnaire for periodontitis was assessed using 50- to 59-yr-old male employees in Japan.

\section{Subjects and Methods}

\section{Subjects}

All 556 males aged 50 to 59, who worked at the Kagawa Police Department, Kagawa Prefecture, Japan, were asked to attend annual dental check-ups by the chief of the department. Because the department operates in three shifts, over one-half of the workers stayed at home or were sleeping when the check-ups were conducted. As a result, a total of 251 males were enrolled in this study. One individual was excluded because he had less than 15 present teeth. The study protocol was approved by the Ethical Committee of the Okayama University Graduate School of Medicine, Dentistry and Pharmaceutical Sciences. Verbal consent was obtained from all participants during the examination period.

\section{Self-reported questionnaire}

Prior to clinical examination by dentists, the participants were asked to complete a self-reported questionnaire regarding smoking status (never smoker, previous smoker or current smoker), signs and symptoms of periodontal disease, and experience of periodontal treatment. The questions were selected based on a systematic review of reports related to validation of selfreported periodontal disease (Table 1$)^{17)}$.

\section{Clinical examination}

Five experienced dentists conducted periodontal examinations according to the protocol of the United States National Health and Nutrition Examination Survey $^{2)}$. Probing pocket depth (PPD) and clinical attachment loss (CAL) were measured at mesio-buccal and mid-buccal sites for all of the teeth in 2 randomly selected quadrants, 1 maxillary and 1 mandibular, using a constant-force periodontal probe (gram probe \#5, TDM Co., Tokyo, Japan). The number of teeth of each participant was also examined. The intra- and interexaminer agreement $( \pm 1 \mathrm{~mm})$, evaluated with kappa statistics, of both PPD and CAL ranged from $98 \%$ to $100 \%$ and from $95 \%$ to $97 \%$, respectively. The distribution of selected quadrants for probing after randomization was as follows: upper right, 131 quadrants; upper left, 119 quadrants; lower right, 115 quadrants; lower left, 135 quadrants.

\section{Statistical analysis}

A periodontitis patient was defined as an individual having at least 1 tooth with severe attachment loss, i.e., $\geq 7 \mathrm{~mm}$ of $\mathrm{CAL}^{14)}$. The sensitivity, specificity, positive and negative likelihood ratios, and crude odds ratio for each question were calculated. Multiple logistic regression analysis was performed to identify questions which were potential predictors of periodontitis. Variables that met the $p<0.10$ criterion were included in a subsequent logistic regression ${ }^{6,14)}$. After calculating the probability of each subject using the equation of the final multiple logistic regression model, a curve of the plot of the sensitivity against 1 -specificity ("receiver operating characteristic" [ROC]) was drawn. The fit of the model was quantified using "c" statistic, which is a measure of the area under the curve ROC $^{14)}$. The sensitivity and specificity of the cut off point of the logistic regression model was determined. Data were analyzed using a statistical package (15.0 J for Windows, SPSS Japan, Tokyo, Japan).

\section{Results}

Among the 250 subjects, 85 (34\%) had never smoked, $74(30 \%)$ were previous smokers, and $91(36 \%)$ were current smokers. The mean (standard deviation) and median (range) number of the teeth present were 27.1 (2.9) and 28 (15-32), respectively. The frequency distribution of subjects in relation to maximum CAL is shown in Fig. 1. The number (percentage) of subjects with CAL $\geq 7 \mathrm{~mm}$ was $33(13 \%)$.

The question "Do you think that you can see more roots of teeth than in the past?" showed the highest sensitivity (0.85) (Table 1). The questions "Are your teeth wobbly?" and "Have you ever been told that you need periodontal or gum treatment?" had the highest specificity (0.83) and the highest positive likelihood ratio (3.10). The highest value of sensitivity plus specificity (1.42) was shown in the question "Do you think that you have gum disease?" Table 1 also showe the crude odds ratio based on the univariate analysis, which indicates that the all items were significantly related to the presence of periodontitis.

The first multiple logistic regression model identified the questions related to the prevalence of periodontitis as "Are you a current or past smoker?", "Have your gums bled recently?", "Do you think that you can see more roots of teeth than in the past?", and "Have you ever been told that you need periodontal or gum treatment?" (Table 2). The final multiple logistic regression model using these 4 questions is shown in Table 3. All questions other than "Are you a current or past smoker?" had $p$ values less than 0.01 . The final multiple logistic equation 


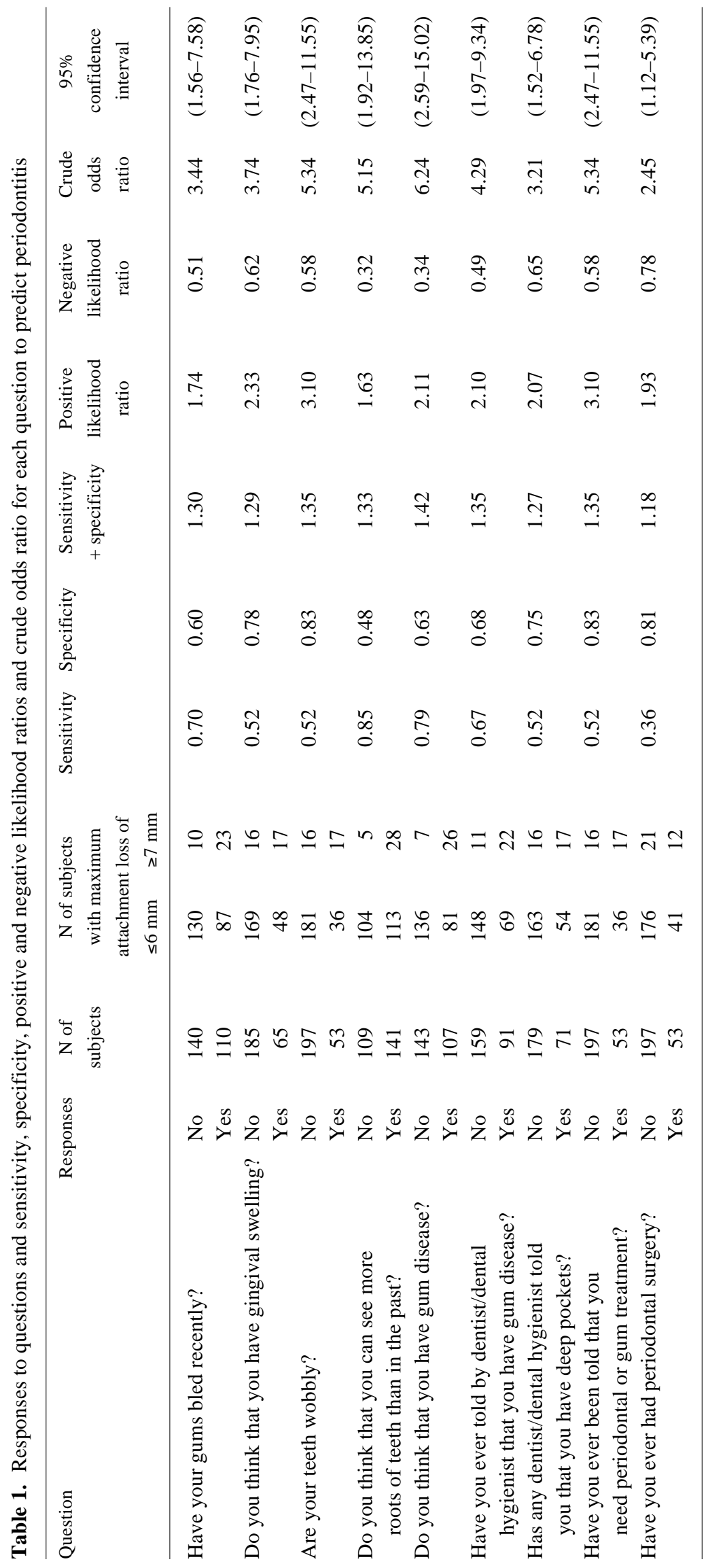






Fig. 1. Frequency distribution of subjects in relation to maximum clinical attachment loss.

Table 2. Multiple logistic regression model (1st model) to predict periodontitis

\begin{tabular}{|c|c|c|c|c|c|}
\hline Question & Beta & Standard error & Odds ratio & $95 \%$ confidence interval & $p$ value \\
\hline Are you a current or past smoker? & 0.954 & 0.550 & 2.60 & $(0.88-7.63)$ & 0.083 \\
\hline Have your gums bled recently? & 1.074 & 0.479 & 2.93 & $(1.15-7.48)$ & 0.025 \\
\hline Do you think that you have gingival swelling? & -0.149 & 0.534 & 0.86 & $(0.30-2.46)$ & 0.780 \\
\hline Are your teeth wobbly? & 0.517 & 0.529 & 1.68 & $(0.60-4.72)$ & 0.328 \\
\hline $\begin{array}{l}\text { Do you think that you can see more } \\
\text { roots of teeth than in the past? }\end{array}$ & 1.111 & 0.566 & 3.04 & $(1.00-9.21)$ & 0.050 \\
\hline Do you think that you have gum disease? & 0.761 & 0.701 & 2.14 & $(0.54-8.47)$ & 0.278 \\
\hline $\begin{array}{c}\text { Have you ever been told by a dentist/dental } \\
\text { hygienist that you have gum disease? }\end{array}$ & 0.156 & 0.673 & 1.17 & $(0.31-4.22)$ & 0.817 \\
\hline $\begin{array}{l}\text { Has any dentist/dental hygienist told } \\
\text { you that you have deep pockets? }\end{array}$ & -0.081 & 0.526 & 0.92 & $(0.33-2.95)$ & 0.878 \\
\hline $\begin{array}{l}\text { Have you ever been told that you } \\
\text { need periodontal or gum treatment? }\end{array}$ & 0.995 & 0.559 & 2.71 & $(0.91-7.72)$ & 0.075 \\
\hline Have you ever had periodontal surgery? & 0.144 & 0.482 & 1.16 & $(0.45-3.07)$ & 0.765 \\
\hline Age (yr) & -0.036 & 0.077 & 0.96 & $(0.83-1.12)$ & 0.635 \\
\hline
\end{tabular}

Table 3. Multiple logistic regression model (final model) to predict periodontitis

\begin{tabular}{|c|c|c|c|c|c|}
\hline Variables & Beta & Standard error & Odds ratio & $95 \%$ confidence interval & $p$ value \\
\hline Are you a current or past smoker? & 0.954 & 0.538 & 2.60 & $(0.90-7.45)$ & 0.076 \\
\hline Have your gums bled recently? & 1.266 & 0.434 & 3.55 & $(1.52-8.30)$ & 0.004 \\
\hline $\begin{array}{l}\text { Do you think that you can see more } \\
\text { roots of teeth than in the past? }\end{array}$ & 1.414 & 0.529 & 4.11 & $(1.46-11.60)$ & 0.008 \\
\hline $\begin{array}{l}\text { Have you ever been told that you } \\
\text { need periodontal or gum treatment? }\end{array}$ & 1.466 & 0.423 & 4.33 & $(1.89-9.92)$ & 0.001 \\
\hline Intercept & -4.767 & 0.722 & - & - & - \\
\hline
\end{tabular}


Table 4. Y values in descending order according to answer patterns

\begin{tabular}{|c|c|c|c|c|c|c|}
\hline \multirow[t]{2}{*}{ Group } & \multicolumn{4}{|c|}{ Answer to each question (yes: 1 , no: 0 ): } & \multirow[t]{2}{*}{$\mathrm{X}$} & \multirow[t]{2}{*}{$\mathrm{Y}$} \\
\hline & $\mathrm{X}_{1}$ & $\mathrm{X}_{2}$ & $\mathrm{X}_{3}$ & $\mathrm{X}_{4}$ & & \\
\hline a & 1 & 1 & 1 & 1 & 0.333 & 0.582 \\
\hline $\mathrm{b}$ & 0 & 1 & 1 & 1 & -0.621 & 0.350 \\
\hline $\mathrm{c}$ & 1 & 0 & 1 & 1 & -0.933 & 0.282 \\
\hline d & 1 & 1 & 0 & 1 & -1.081 & 0.253 \\
\hline $\mathrm{e}$ & 1 & 1 & 1 & 0 & -1.133 & 0.244 \\
\hline $\mathrm{f}$ & 0 & 0 & 1 & 1 & -1.887 & 0.132 \\
\hline $\mathrm{g}$ & 0 & 1 & 0 & 1 & -2.035 & 0.116 \\
\hline $\mathrm{h}$ & 0 & 1 & 1 & 0 & -2.087 & 0.110 \\
\hline $\mathrm{i}$ & 1 & 0 & 0 & 1 & -2.347 & 0.087 \\
\hline $\mathrm{j}$ & 1 & 0 & 1 & 0 & -2.399 & 0.083 \\
\hline $\mathrm{k}$ & 1 & 1 & 0 & 0 & -2.547 & 0.073 \\
\hline 1 & 0 & 0 & 0 & 1 & -3.301 & 0.036 \\
\hline $\mathrm{m}$ & 0 & 0 & 1 & 0 & -3.353 & 0.034 \\
\hline $\mathrm{n}$ & 0 & 1 & 0 & 0 & -3.501 & 0.029 \\
\hline o & 1 & 0 & 0 & 0 & -3.813 & 0.022 \\
\hline $\mathrm{p}$ & 0 & 0 & 0 & 0 & -4.767 & 0.008 \\
\hline
\end{tabular}

The final multiple logistic model is

$\mathrm{Y}=\exp (\mathrm{X}) /\{1+\exp (\mathrm{X})\}$

$\mathrm{X}=0.954 \mathrm{X}_{1}+1.266 \mathrm{X}_{2}+1.414 \mathrm{X}_{3}+1.466 \mathrm{X}_{4}-4.767$

where $\mathrm{Y}$ is a dependent variable, and $\mathrm{X}_{1}, \mathrm{X}_{2}, \mathrm{X}_{3}$ and $\mathrm{X}_{4}$ are the binary responses to the 4 questions in Table 3 .

was

$$
\begin{aligned}
& \mathrm{Y}=\exp (\mathrm{X}) /\{1+\exp (\mathrm{X})\} \\
& \mathrm{X}=0.954 \mathrm{X}_{1}+1.266 \mathrm{X}_{2}+1.414 \mathrm{X}_{3}+1.466 \mathrm{X}_{4}-4.767
\end{aligned}
$$

where $\mathrm{Y}$ was a dependent variable. $\mathrm{X}_{1}, \mathrm{X}_{2}, \mathrm{X}_{3}$ and $\mathrm{X}_{4}$ were coded 1 and 0 if the answer of the following 4 questions was "yes" and "no," respectively.

$\mathrm{X}_{1}$ : Are you a current or past smoker?

$\mathrm{X}_{2}$ : Have your gums bled recently?

$\mathrm{X}_{3}$ : Do you think that you can see more roots of teeth than in the past?

$\mathrm{X}_{4}$ : Have you ever been told that you need periodontal or gum treatment?

All the patterns of response $(n=16)$ to the questions were calculated using the equation (Table 4 ). The subjects were divided into two groups according to the $\mathrm{Y}$ value. When the groups $a+b+c+d+e$, i. e., the subjects with at least 3 responses of "yes," were separated from the others, the subjects with periodontitis were separated most effectively (showing the highest sensitivity + specificity) from those without (Table 5). At the optimum point, sensitivity, specificity, and positive and negative likelihood ratios were $0.73,0.80,3.58$ and 0.34 , respectively. The area under the ROC curve was 0.81 .

\section{Discussion}

The logistic regression model using the 4 questions provided a useful measure for screening periodontitis with respect to the level of predictive validity using the "c" statistic and values for sensitivity and specificity. When subjects with at least 3 "yes" responses were separated from those with 2 or fewer responses of "yes," subjects with periodontitis were separated most effectively from those without. The area under the ROC curve was 0.81 , which is classified as "useful for some purpose" ${ }^{18)}$. The combined sensitivity and specificity (1.53) indicates good validity because the value is more than $1.20^{17}$. The values obtained in the present study are within the range of other questionnaire studies using a similar logistic regression model $^{6,13-16)}$.

Recently, lactate dehydrogenase in saliva was proposed as a new screening measure of periodontal disease ${ }^{19}$. However, the sensitivity (0.73) and specificity (0.80) of the final logistic regression model in the present study were higher than those of lactate dehydrogenase in saliva (sensitivity: 0.66, specificity: 0.67). Moreover, determination of lactate dehydrogenase in saliva is relatively expensive and requires various equipment. Therefore, the questionnaire would be useful for screening for periodontitis in a workplace.

The questions "Are you a current or past smoker?", "Have your gums bled recently?", "Do you think that you can see more roots of teeth than in the past?", and "Have you ever been told that you need periodontal or gum treatment?" were useful for predicting periodontal disease outcomes. Three out of the 4 questions were for dental variables and the other was for smoking status. These 3 dental questions could be added to a medical 
Table 5. Sensitivity and specificity of each cut off

\begin{tabular}{lccc}
\hline Group which were categolized into periodontitis & Sensitivity & Specificity & $\begin{array}{r}\text { Sensitivity + } \\
\text { specificity }\end{array}$ \\
\hline $\mathrm{a}$ & & & 1.275 \\
$\mathrm{a}+\mathrm{b}$ & 0.303 & 0.972 & 1.262 \\
$\mathrm{a}+\mathrm{b}+\mathrm{c}$ & 0.303 & 0.959 & 1.336 \\
$\mathrm{a}+\mathrm{b}+\mathrm{c}+\mathrm{d}$ & 0.424 & 0.912 & 1.349 \\
$\mathrm{a}+\mathrm{b}+\mathrm{c}+\mathrm{d}+\mathrm{e}^{*}$ & 0.455 & 0.894 & 1.524 \\
$\mathrm{a}+\mathrm{b}+\mathrm{c}+\mathrm{d}+\mathrm{e}+\mathrm{f}$ & 0.727 & 0.797 & 1.506 \\
$\mathrm{a}+\mathrm{b}+\mathrm{c}+\mathrm{d}+\mathrm{e}+\mathrm{f}+\mathrm{g}$ & 0.727 & 0.779 & 1.492 \\
$\mathrm{a}+\mathrm{b}+\mathrm{c}+\mathrm{d}+\mathrm{e}+\mathrm{f}+\mathrm{g}+\mathrm{h}$ & 0.727 & 0.765 & 1.488 \\
$\mathrm{a}+\mathrm{b}+\mathrm{c}+\mathrm{d}+\mathrm{e}+\mathrm{f}+\mathrm{g}+\mathrm{h}+\mathrm{i}$ & 0.788 & 0.700 & 1.500 \\
$\mathrm{a}+\mathrm{b}+\mathrm{c}+\mathrm{d}+\mathrm{e}+\mathrm{f}+\mathrm{g}+\mathrm{h}+\mathrm{i}+\mathrm{j}$ & 0.818 & 0.682 & 1.372 \\
$\mathrm{a}+\mathrm{b}+\mathrm{c}+\mathrm{d}+\mathrm{e}+\mathrm{f}+\mathrm{g}+\mathrm{h}+\mathrm{i}+\mathrm{j}+\mathrm{k}$ & 0.879 & 0.493 & 1.315 \\
$\mathrm{a}+\mathrm{b}+\mathrm{c}+\mathrm{d}+\mathrm{e}+\mathrm{f}+\mathrm{g}+\mathrm{h}+\mathrm{i}+\mathrm{j}+\mathrm{k}+\mathrm{l}$ & 0.909 & 0.406 & 1.335 \\
$\mathrm{a}+\mathrm{b}+\mathrm{c}+\mathrm{d}+\mathrm{e}+\mathrm{f}+\mathrm{g}+\mathrm{h}+\mathrm{i}+\mathrm{j}+\mathrm{k}+\mathrm{l}+\mathrm{m}$ & 0.939 & 0.396 & 1.302 \\
$\mathrm{a}+\mathrm{b}+\mathrm{c}+\mathrm{d}+\mathrm{e}+\mathrm{f}+\mathrm{g}+\mathrm{h}+\mathrm{i}+\mathrm{j}+\mathrm{k}+\mathrm{l}+\mathrm{m}+\mathrm{n}$ & 0.970 & 0.332 & 1.223 \\
$\mathrm{a}+\mathrm{b}+\mathrm{c}+\mathrm{d}+\mathrm{e}+\mathrm{f}+\mathrm{g}+\mathrm{h}+\mathrm{i}+\mathrm{j}+\mathrm{k}+\mathrm{l}+\mathrm{m}+\mathrm{n}+\mathrm{o}$ & 0.970 & 0.253 & 1.076 \\
$\mathrm{a}+\mathrm{b}+\mathrm{c}+\mathrm{d}+\mathrm{e}+\mathrm{f}+\mathrm{g}+\mathrm{h}+\mathrm{i}+\mathrm{j}+\mathrm{k}+\mathrm{l}+\mathrm{m}+\mathrm{n}+\mathrm{o}+\mathrm{p}$ & 0.970 & 0.106 & 1.000 \\
\hline
\end{tabular}

Answer pattern of each group was shown in Table 4.

*Optimal point of cut-off.

health questionnaire, such as the questionnaire for metabolic syndrome. In April 2008, a new healthcare system reform including health check-up and lifestyle intervention was introduced to prevent metabolic syndrome in Japan. Because metabolic syndrome and periodontal disease share common risk factors ${ }^{20)}$, an approach to integrate interventions for periodontal health into medical health programs is recommended ${ }^{21}$. Questionnaires for the prevention of metabolic syndrome, which include the abovementioned 3 dental questions, might serve as an effective approach in workplaces.

Partial examination, not full-mouth examination, was carried out in this study. Because this study was conducted as a part of dental health promotion activities in a workplace, we did not have adequate time to examine the whole mouth. Recent studies defined severe periodontitis as having 2 or more teeth with $\mathrm{CAL} \geq 6 \mathrm{~mm}$ and at least one site with PPD $\geq 5 \mathrm{~mm}$, and moderate periodontitis as having at least 2 sites with $\mathrm{CAL} \geq 4 \mathrm{~mm}$ on 2 different teeth or at least 2 sites with PPD $\geq 5 \mathrm{~mm}$ on 2 different teeth based on full-mouth examination ${ }^{6,15,16)}$. Some studies used panoramic radiographs ${ }^{13)}$ and intra oral radiographs ${ }^{10)}$ to define periodontal disease. We conducted partial mouth examination, and this examination methodology might have underestimated the prevalence of periodontitis and led to misclassification of the periodontal status. Such misclassification might have contributed to attenuation of the area under the ROC curve, and the sensitivity and specificity of the logistic regression model of the present study.
We defined the subjects with at least one tooth having CAL of $7 \mathrm{~mm}$ or more as periodontitis patients. The purpose of this study was to screen severe periodontitis rather than mild periodontitis and gingivitis. Severe periodontitis is a main cause of tooth loss ${ }^{1}$, which reduces quality of life. In addition, severe periodontitis is a risk factor of cardiovascular disease, stroke, diabetes and pulmonary disease ${ }^{22}$. Therefore, screening severe periodontitis is important to prevent tooth loss and related systemic diseases.

When a subject with at least one site of PPD $\geq 5 \mathrm{~mm}$ was defined as having periodontitis, the questions with highest sensitivity and specificity were identical with those when $\mathrm{CAL} \geq 7 \mathrm{~mm}$ was defined as having periodontitis. However, the first logistic regression analysis showed that only one question "Do you think that you can see more roots of teeth than in the past?" was significantly associated with periodontitis $(p<0.10)$, while the other questions were not. The difference of the results according to the definition of periodontitis might be ascribable to the difference of meaning between PPD and CAL. PPD represents present status of periodontium, but CAL measures previous disease experience ${ }^{23}$. For example, it is possible that a tooth has $<5 \mathrm{~mm}$ of PPD, even though it has CAL $\geq 7 \mathrm{~mm}$.

Only 50- to 59-yr-old males participated in the study. Future studies including other age groups and females would be required to test the universal application of the questionnaire. We excluded female workers from the study subjects because the number of females was only 
25. In addition, because males are more susceptible to periodontitis than females ${ }^{24)}$, we focused on males in this study. Another limitation of the study was that the subjects were workers at a police department, who might not be representative of a general population. Therefore, extrapolation of the results to the general population must be carried out carefully. Moreover, addition of variables such as diabetes ${ }^{16}$, which are established risk factors of periodontal disease, may improve the logistic regression model. However, we could not include such data related to diabetes in the present study.

In conclusion, a logistic regression model using four self-reported questions, such as "Are you a current or past smoker?", "Have your gums bled recently?", "Do you think that you can see more roots of teeth than in the past?", and "Have you ever been told that you need periodontal or gum treatment?" would be useful for screening for periodontitis in 50- to 59-yr-old Japanese males in workplaces.

\section{References}

1) Aida J, Ando Y, Akhter R, Aoyama H, Masui M, Morita M. Reasons for permanent tooth extractions in Japan. J Epidemiol 2006; 16: 214-9.

2) Brown LJ, Brunelle JA, Kingman A. Periodontal status in the United States, 1988-91: prevalence, extent, and demographic variation. J Dent Res 1996; 75 (Spec Iss): 672-83.

3) Kimura H, Goda K, Takeda N, Hirao T, Fukunaga I, Kageyama H, Jitsunari F. Oral health promotion in the workplace and relative factors. J Dent Hlth 2001; 51: 37-47 (in Japanese).

4) Cutress TW, Ainamo J, Sardo-Infirri J. The community periodontal index of treatment needs (CPITN) procedure for population groups and individuals. Int Dent J 1987; 37: 222-33.

5) Perry DA, Taggart EJ, Leung A, Newbrun E. Comparison of a conventional probe with electric and manual pressure-regulated probes. J Periodontol 1994; 65: 908-13.

6) Taylor GW, Borgnakke WS. Self-reported periodontal disease: validation in an epidemiological survey. J Periodontol 2007; 78 (Suppl), 1407-20.

7) Joshipura KJ, Douglass CW, Garcia RI, Valachovic R, Willett WC. Validity of a self-reported periodontal disease measure. J Public Health Dent 1996; 56: 20512.

8) Joshipura KJ, Pitiphat W, Douglass CW. Validation of self-reported periodontal measures among health professionals. J Public Health Dent 2002; 62: 115-21.

9) Gilbert AD, Nuttall NM. Self-reporting of periodontal health status. Br Dent J 1999; 186: 241-4.
10) Pitiphat W, Garcia RI, Douglass CW, Joshipura KJ. Validation of self-reported oral health measures. J Public Health Dent 2002; 62: 122-8.

11) Buhlin K, Gustafsson A, Andersson K, Håkansson J, Klinge B. Validity and limitations of self-reported periodontal health. Community Dent Oral Epidemiol 2002; 30: 431-7.

12) Dietrich $T$, Stosch U, Dietrich $D$, Schamberger D, Bernimoulin J-P, Joshipura K. The accuracy of individual self-reported items to determine periodontal disease history. Eur J Oral Sci 2005; 113: 135-40.

13) Dietrich T, Stosch U, Dietrich D, Kaiser W, Bernimoulin JP, Joshipura K. Prediction of periodontal disease from multiple self-reported items in a German practice-based sample. J Periodontol 2007; 78 (Suppl): 1421-8.

14) Gilbert GH, Litaker MS. Validity of self-reported periodontal status in the Florida Dental Care Study. J Periodontol 2007; 78 (Suppl): 1429-38.

15) Genco RJ, Falkner KL, Grossi S, Dunford R, Trevisan M. Validity of self-reported measures for surveillance of periodontal disease in two western New York population-based studies. J Periodontol 2007; 78 (Suppl): 1439-54.

16) Slade GD. Interim analysis of validity of periodontitis screening questions in the Australian population. J Periodontol 2007; 78 (Suppl): 1463-70.

17) Blicher B, Joshipura K, Eke P. Validation of selfreported periodontal disease: a systematic review. J Dent Res 2005; 84: 881-90.

18) Swets JA. Measuring the accuracy of diagnostic systems. Science 1988; 240: 1285-93.

19) Nomura Y, Tamaki Y, Tanaka T, et al. Screening of periodontitis with salivary enzyme tests. J Oral Sci 2006; 48: 177-83.

20) Shimazaki Y, Saito T, Yonemoto K, Kiyohara Y, Iida M, Yamashita Y. Relationship of metabolic syndrome to periodontal disease in Japanese women: the Hisayama study. J Dent Res 2007; 86: 271-5.

21) Petersen PE, Yamamoto T. Improving the oral health of older people: the approach of the WHO Global Oral Health Programme. Community Dent Oral Epidemiol 2005; 33: 81-92.

22) Pihlstrom BL, Michalowicz BS, Johnson NW. Periodontal diseases. Lancet 2005; 366: 1809-20.

23) Tomofuji T, Azuma T, Kusano H, et al. Role of measurement of probing depth and attachment level in periodontal patients. Nippon Shishubyo Gakkai Kaishi 2004; 46: 253-8 (in Japanese).

24) Statistical Analysis Committee on the Survey of Dental Diseases, editor. Comprehensive guide to the survey of dental diseases (2005). Tokyo (Japan): Oral Health Association of Japan; 2007. p.104-5. 